\title{
The role of asenapine in the treatment of manic or mixed states associated with bipolar I disorder
}

\author{
This article was published in the following Dove Press journal: \\ Neuropsychiatric Disease and Treatment \\ 4 May 201I \\ Number of times this article has been viewed
}

\section{Maurizio Pompili ${ }^{1,2}$ \\ Paola Venturini' \\ Marco Innamorati' \\ Gianluca Serafini' \\ Ludovica Telesforo' \\ David Lester ${ }^{3}$ \\ Roberto Tatarelli' \\ Paolo Girardi'}

'Department of Neurosciences, Mental Health and Sensory

Functions, Suicide Prevention Center,

Sant'Andrea Hospital, Sapienza

University of Rome, Rome, Italy;

${ }^{2}$ McLean Hospital, Harvard Medical

School, Boston, MA, USA; ${ }^{3}$ The

Richard Stockton College of New

Jersey, Pomona, NJ, USA
Correspondence: Maurizio Pompili Department of Psychiatry, Sant'Andrea Hospital, Sapienza University of Rome, I035 Via di Grottarossa, 00189 Roma, Italy

Tel +39063 3775675

Fax +39063 3775342

Email maurizio.pompili@uniromal.it
Background: Bipolar disorders (BD) are of particular public health significance as they are prevalent, severe and disabling, and often associated with elevated risks of premature mortality. The aim of this concise overview is to investigate the role of asenapine in the treatment of manic and mixed states associated with BD type 1 disorder.

Method: MedLine, Excerpta Medica and PsycINFO searches were performed to identify papers in English published over the past 7 years. Search terms were "asenapine", "manic" OR "mixed states", "bipolar I disorder". Subjects included in this study suffered from BD type 1 disorder.

Results: To date, only four studies of asenapine for the treatment of manic or mixed episodes associated with BD type 1 have been published.

Conclusion: Research indicates that asenapine is generally well-tolerated, and that asenapine is efficacious and not inferior to olanzapine in the treatment of mixed or manic episodes associated with BD type 1 in the short-term and long-term.

Keywords: asenapine, bipolar disorder, side effects

\section{Introduction}

Bipolar disorders (BD) are of particular public health significance as they are prevalent, severe and disabling, and often associated with elevated risks of premature mortality, adverse medical outcomes, accidents, and complications from comorbid substance use disorders. ${ }^{1}$

The World Health Organization reported, in 2001, that bipolar disorder was the fifth cause of years lived with disability among young adults. BD is characterized by periods of mania, depression, or mixed episodes, often multiple times during a lifetime. Mania is the most characteristic phase of bipolar disorder, and a major cause of disability, stigma and cognitive impairment. Lithium is the traditional treatment option, but the majority of patients do not respond to lithium monotherapy. Other drugs have been introduced in recent years, such as the anticonvulsants valproate and carbamazepine, some typical antipsychotics (eg, haloperidol, chlorpromazine), atypical antipsychotics (such as quetiapine, olanzapine, risperidone, ziprasidone, aripiprazolo and clozapine), and benzodiazepines (eg, lorazepam and clonazepam). ${ }^{2}$

Therapy for mood disorders is a major problem in psychiatry despite the availability of effective treatments. Mood disorders frequently remain undiagnosed and, even if recognized, treatment duration and dosage are often inadequate and adherence to the medication regimen is poor. ${ }^{3}$ Greater antidepressant adherence has been linked to greater response and remission among depressed subjects, ${ }^{3}$ whereas nonadherence has been shown to be related to less improvement of depressive symptoms and 


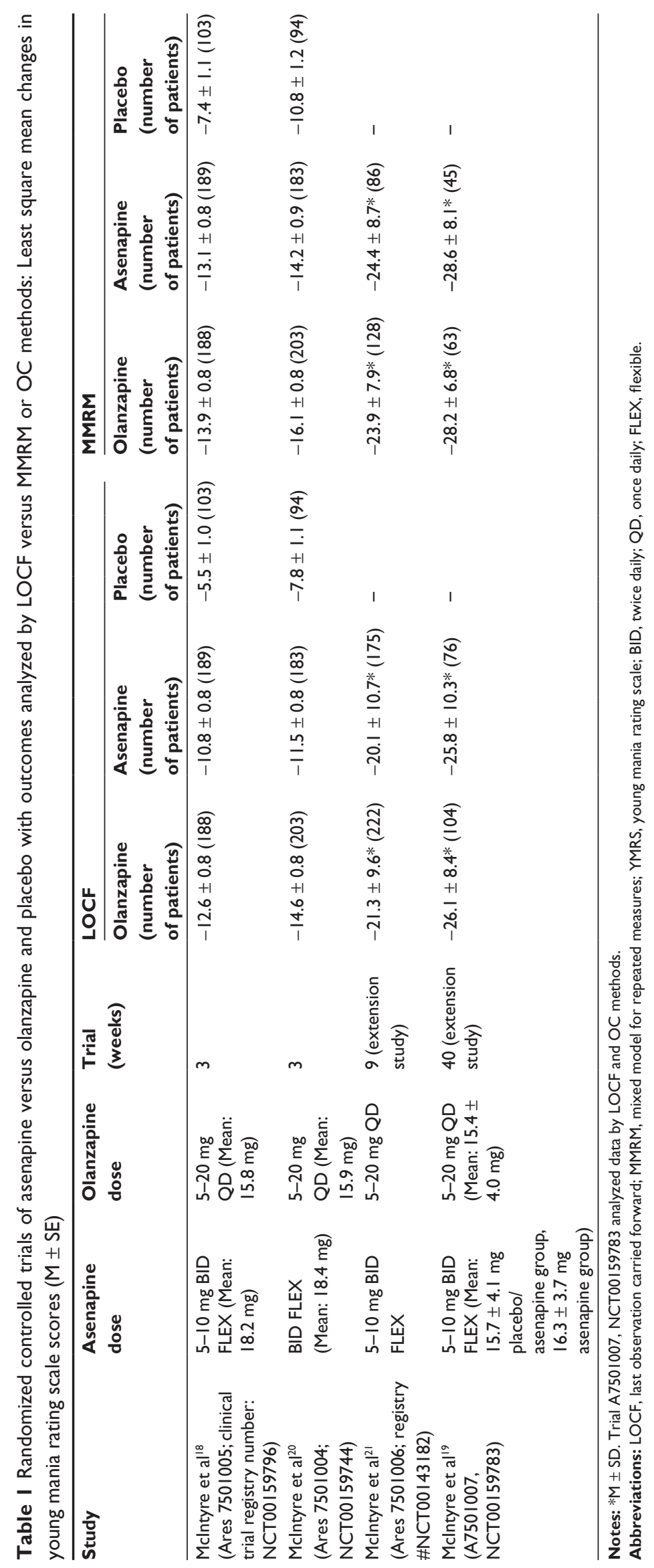




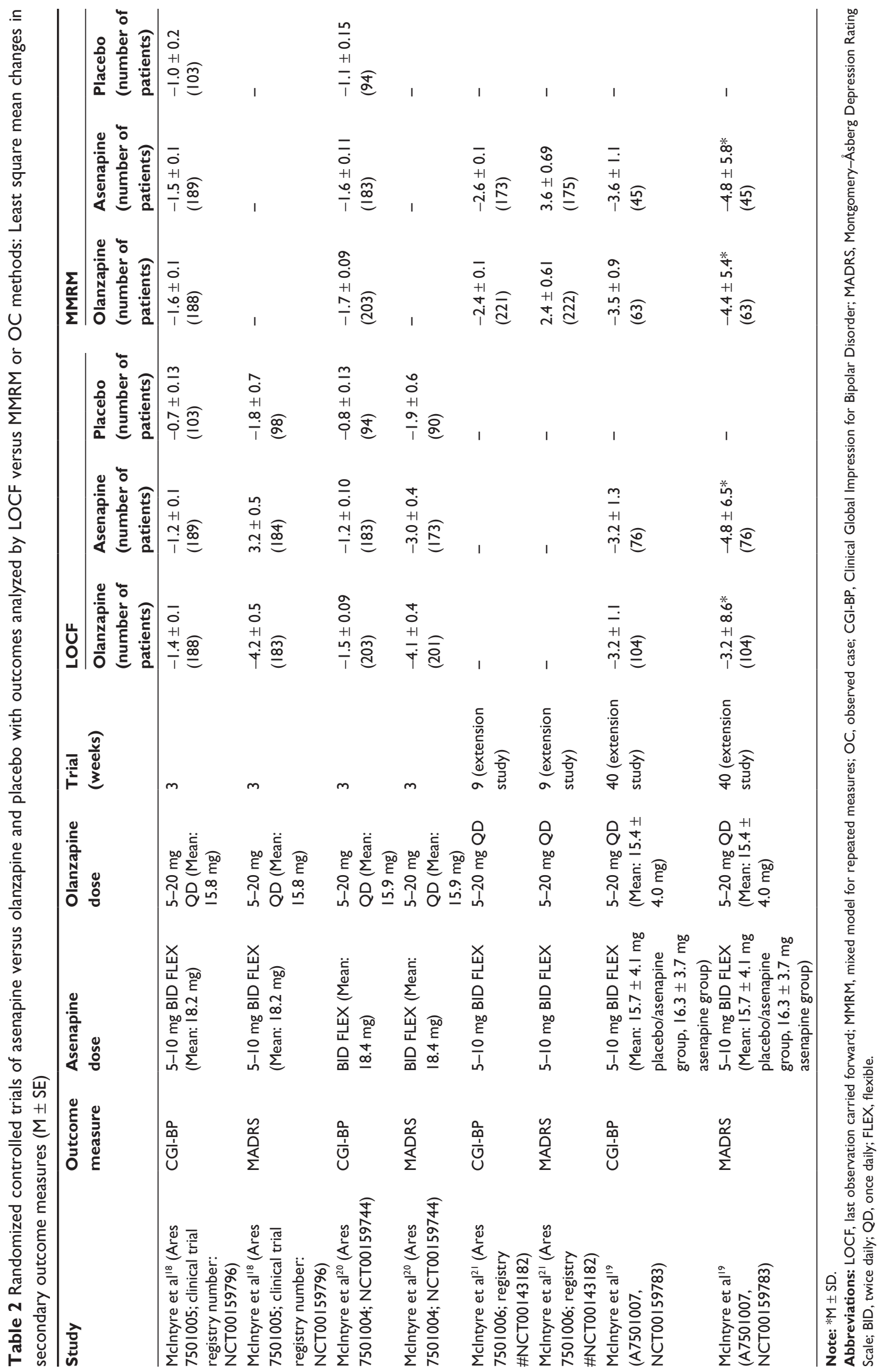


Table 3 Randomized controlled trials of asenapine versus olanzapine and placebo: adverse events

\begin{tabular}{|c|c|c|c|c|c|c|}
\hline \multirow[t]{2}{*}{ Study } & \multirow[t]{2}{*}{ Asenapine dose } & \multirow[t]{2}{*}{ Olanzapine dose } & \multirow[t]{2}{*}{ Trial (weeks) } & \multicolumn{3}{|c|}{ Treatment-related adverse events } \\
\hline & & & & Olanzapine & Asenapine & Placebo \\
\hline $\begin{array}{l}\text { Mclntyre et al } 18 \\
\text { (Ares } 7501005 ; \\
\text { clinical trial } \\
\text { registry number: } \\
\text { NCT00I59796) }\end{array}$ & $\begin{array}{l}\text { 5-10 mg BID FLEX } \\
\text { (Mean: I8.2 mg) }\end{array}$ & $\begin{array}{l}\text { 5-20 mg QD } \\
\text { (Mean: I5.8 mg) }\end{array}$ & 3 & $52.9 \%$ & $60.8 \%$ & $36.2 \%$ \\
\hline $\begin{array}{l}\text { Mclntyre et } \mathrm{al}^{20} \\
(\text { Ares } 750 \mathrm{I} 004 ; \\
\text { NCT00I59744) }\end{array}$ & $\begin{array}{l}\text { BID FLEX (Mean: } \\
\text { I8.4 mg) }\end{array}$ & $\begin{array}{l}\text { 5-20 mg QD } \\
\text { (Mean: I5.9 mg) }\end{array}$ & 3 & $46.8 \%$ & $55.1 \%$ & $27.6 \%$ \\
\hline $\begin{array}{l}\text { Mclntyre et } \mathrm{al}^{21} \\
\text { (Ares } 7501006 ; \\
\text { registry } \\
\text { \#NCT00।43।82) }\end{array}$ & 5-10 mg BID FLEX & 5-20 mg QD & $\begin{array}{l}9 \text { (extension } \\
\text { study) }\end{array}$ & $64 \%(53 \%)^{*}$ & $65 \%$ & - \\
\hline $\begin{array}{l}\text { Mclntyre et al }{ }^{19} \\
\text { (A750 I007, } \\
\text { NCT00I59783) }\end{array}$ & $\begin{array}{l}\text { 5-10 mg BID FLEX } \\
\text { (Mean: I5.7 } \pm 4.1 \mathrm{mg} \\
\text { placebo/asenapine group, } \\
16.3 \pm 3.7 \mathrm{mg} \text { asenapine } \\
\text { group) }\end{array}$ & $\begin{array}{l}\text { 5-20 mg QD } \\
\text { (Mean: I5.4 } \pm 4.0 \mathrm{mg} \text { ) }\end{array}$ & $\begin{array}{l}40 \text { (extension } \\
\text { study) }\end{array}$ & $61.7 \%(53.1 \%)^{*}$ & $70.9 \%$ & - \\
\hline
\end{tabular}

greater relapse/recurrence of depression. ${ }^{4-7}$ It is estimated that nonadherence ranges from $10 \%$ to $60 \%$ in mood disorders, with a median of $40 \%{ }^{8}$ However, according to Lingam and Scott, ${ }^{8}$ this topic is understudied, and only $1 \%-2 \%$ of all publications on the treatment of affective disorders explore factors associated with medication nonadherence.

$\mathrm{BD}$ is associated with high levels of long-term morbidity, comorbidity, hospitalization, disability, and increased mortality rates resulting from suicide, accidents, adverse outcomes of comorbid substance use and abuse, and medical illnesses. ${ }^{9-13}$ Nonadherence with medication regimens appears to contribute substantially to worse outcomes and possibly to treatment failures among patients with BD. Antipsychotics are commonly used in the treatment of BD. All currently approved antipsychotic drugs block dopamine D2 receptors, and all atypical antipsychotics are also more potent antagonists of the 5-hydroxytryptamine receptor 2A (5-HT2A). ${ }^{14}$

Asenapine (Saphris ${ }^{\circledR}$ ) is a second-generation antipsychotic, which received regulatory approval in August 2009 by the US Food and Drug Administration (FDA) for the acute treatment of schizophrenia and for the acute treatment of manic or mixed episodes associated with BD-I disorder in adults. Originally developed by Organon, asenapine was initially known as ORG 52222. The first substantive mention of the molecule in the published literature is an animal study published in 1990 that suggested that it had antipsychotic and anxiolytic potential related to dopamine and serotonin receptor antagonism. It was investigated originally in Europe and
Japan in intravenous and oral formulations, but because of low bioavailability and high hepato-gastrointestinal first-pass metabolism of the oral formulation, a sublingual dosage form was developed. The development of sublingual asenapine began in 1996 for the treatment of schizophrenia, and in 2004 for the treatment of bipolar disorder. Asenapine is classified as a dibenzo-oxepino pyrrole and has properties that are most similar to those of quetiapine, olanzapine, and clozapine. ${ }^{15}$

As with other antipsychotic agents, asenapine exhibits a higher binding affinity for the 5HT2A receptor compared with D2 receptors. Moreover, asenapine has a broad range of effects on other neurotransmitter systems including 5-HT2c, 5-HT7, 5-HT2b, 5-HT6, 5-HT1a, 5-HT1b, $\alpha 2 b$, $\alpha 1 \mathrm{a}, \alpha 2 \mathrm{a}, \alpha 2 \mathrm{c}, \mathrm{D} 3, \mathrm{D} 4, \mathrm{D} 21, \mathrm{D} 1, \mathrm{D} 2 \mathrm{~s}$, and $\mathrm{H} 2$ receptors. One major difference between asenapine and most other atypical antipsychotics (except for risperidone, ziprasidone and aripiprazolo) is that it exhibits little muscarinic receptor antagonist effects, which may produce a less cognitively deleterious profile, but it may result in weight gain. Given that D2 receptor occupancy has been deemed as vital for antipsychotic efficacy, it is important to note that $5 \mathrm{mg}$ tablets result in roughly $75 \%$ D2 occupancy, while occupancy is $85 \%$ with $10 \mathrm{mg}$ tablets.

The sublingual administration results in a rapid absorption with peak plasma concentrations within $0.5-1.5$ hours and moderate $(35 \%)$ bioavailability. This is in the low to mid-range of other antipsychotics, which exhibit 20\%-70\% 


\begin{tabular}{|c|c|c|c|c|c|c|c|c|}
\hline \multicolumn{3}{|l|}{ Discontinued } & \multicolumn{3}{|c|}{ Discontinued because of adverse events } & \multicolumn{3}{|c|}{ Discontinued because of lack of efficac } \\
\hline Olanzapine & Asenapine & Placebo & Olanzapine & Asenapine & Placebo & Olanzapine & Asenapine & Placebo \\
\hline $30.9 \%$ & $37.1 \%$ & $38.5 \%$ & $4.2 \%$ & $10.3 \%$ & $6.7 \%$ & $5.8 \%$ & $8.2 \%$ & $16.3 \%$ \\
\hline $21.5 \%$ & $33.0 \%$ & $41.8 \%$ & $3.4 \%$ & $9.2 \%$ & $4.1 \%$ & $6.3 \%$ & $7.6 \%$ & $14.3 \%$ \\
\hline $36.2 \%$ & $38.1 \%(46.8 \%)^{*}$ & - & $9.6 \%$ & $13.3 \%(19.2 \%)^{*}$ & - & $3.9 \%$ & $3.3 \%(5.3 \%)^{*}$ & - \\
\hline $36.4 \%$ & $34.2 \%(59.4 \%)^{*}$ & - & $8.4 \%$ & $8.9 \%(15.6 \%)^{*}$ & - & $2.8 \%$ & $2.5 \%(3.1 \%)^{*}$ & - \\
\hline
\end{tabular}

Note: *Placebo/Asenapine group.

Abbreviations: LOCF, last observation carried forward; MMRM, mixed model for repeated measures; OC, observed case; CGI-BP, Clinical Global Impression for Bipolar Disorder; MADRS, Montgomery-Åsberg Depression Rating Scale; BID, twice daily; QD, once daily; FLEX, flexible.

bioavailability at appropriate doses. The primary metabolic pathways of asenapine are direct glucuronidation by glucuronidyl transferases and oxidative metabolism by cytochrome P450 isoenzymes. Thus, coadministration of asenapine with known inhibitors, inducers or substrates of these metabolic pathways, including the CYP1A2 inhibitor fluvoxamine, can alter the metabolism of asenapine. However such interactions are not uncommon among atypical antipsychotics. Importantly, given the high incidence of smoking, smoking during administration does not alter the pharmacokinetics of asenapine. The reduced bioavailability via oral consumption means, however, that eating or drinking within 10 minutes can alter the bioavailability of asenapine. ${ }^{16}$

The aim of this concise overview is to investigate the role of asenapine, a new second-generation antipsychotic agent, in the treatment of manic and mixed states associated with BD-I disorder.

\section{Methods}

In order to provide a new, timely and concise mini-review of asenapine in the treatment of manic and mixed states associated with BD disorder, we performed careful MedLine, Excerpta Medica and PsycInfo searches to identify papers published in English over the past 7 years. Search terms were "asenapine", "manic", "mixed states", "bipolar I disorder". Each term was also cross-referenced with the others using the MeSH method (Medical Subjects Headings).
The selection of trials for inclusion in the review was firstly performed by the principal reviewer (MP) followed by a further independent (blind to each other) review by the other authors after employing the search strategy described previously. Where a title or abstract appeared to describe a trial eligible for inclusion, the full article was obtained and inspected to assess relevance to this review based on the inclusion criteria. The principal author independently decided whether these met the review criteria. No blinding to the names of authors, institutions and journal of publication took place. Any discrepancies between the two reviewers were resolved by consultations with senior colleagues. When this proved impossible, we sought further information and, in the interim, added these trials to the 'Awaiting assessment' list. The reference list was further modified on the basis of comments from peer reviewers.

Patients included in this review were adult ( $\geq 18$ years old) with a current Diagnostic and Statistical Manual of Mental Disorders, Fourth Edition (DSM-IV) primary diagnosis of bipolar I disorder who were experiencing manic or mixed episodes.

\section{Clinical efficacy and safety}

The FDA approved asenapine based on the efficacy outcomes from four clinical trials (two studies of acute schizophrenia and two studies of mania/mixed episodes of BD-I). These pivotal trials were supported by a number of other studies that also contributed safety data. The briefing documents, 
prepared by the FDA, reported 51 completed trials and 12 ongoing clinical trials in the asenapine clinical program. Of these, 29 are clinical pharmacology studies in healthy subjects and subjects with renal or hepatic impairment, and eight are clinical pharmacology studies in subjects with schizophrenia or schizoaffective disorder. This leaves 14 completed Phase II and III studies of asenapine in schizophrenia and bipolar mania. Very little of this research has been published in peer-reviewed journals, and only some has appeared in posters and presentations. However, the briefing documents available do provide sufficient detail to allow an appraisal of the evidence regarding the efficacy and tolerability of asenapine. ${ }^{17}$

\section{Clinical trials}

To date, only four studies of asenapine for the treatment of manic or mixed episodes associated with BD-I have been published. These are four progressive trials, conducted by McIntyre et al, that analyzed asenapine's efficacy, tolerability, and safety in both the short-term and long-term ${ }^{18-21}$ (Tables 1-3).

Eligible patients were adults who met Diagnostic and Statistical Manual, Fourth Edition (DSM-IV) criteria for BD-I and who were experiencing manic or mixed episodes. The authors conducted two identical 3-week, randomized, double-blind, placebo controlled trials with 488 and 489 patients respectively. They were randomly assigned to flexible-dose sublingual asenapine (5 or $10 \mathrm{mg}$ ), oral olanzapine (5-20 mg) or placebo. The patients who completed the trials were eligible for a 9-week, double-blind extension study (504 patients) that did not include a placebo arm and, finally, those who completed this extension study could enter a 40-week extension study (218 patients). Efficacy evaluations were made using the Young Mania Rating Scale (YMRS). ${ }^{22}$ Tolerability and safety assessment included adverse effects, physical examinations, extrapyramidal symptom ratings, and laboratory tests.

In both studies, no significant differences were identified between olanzapine and asenapine when compared with placebo in the YMRS total score. In the first study, YMRS response and remission rates with olanzapine, but not with asenapine, were greater than placebo but, in the second study, both drugs, olanzapine and asenapine were superior to placebo. Discontinuation rates (for reasons such as extrapyramidal-related adverse effects) were generally low in both trials, with no significant differences between the groups. In both trials, a poor weight gain profile was observed in the olanzapine group when compared with the asenapine and placebo groups. Changes from baseline in metabolic chemistries, laboratory tests and vital signs were generally small and not clinically relevant, although prolactin levels were slightly greater with olanzapine than with asenapine. ${ }^{18-21,23}$ Long-term efficacy and safety were investigated during the 9-week and 40-week double blind extension studies. In these studies, asenapine was not inferior to olanzapine for changes from baseline in YMRS total score, but clinically significant weight gain was greater with olanzapine than asenapine.

The use of asenapine was also studied in a trial as adjunctive treatment for acute mania associated with BD-I. In this randomized, controlled trial, adjunctive asenapine significantly improved the symptoms of BD-I in adult patients not fully responsive to pre-existing mood stabilizers. ${ }^{24}$

\section{Conclusion}

Research indicates that asenapine is generally well-tolerated, with no significant differences between groups in terms of adverse events or extrapyramidal symptoms in the shortterm and long-term. In all four trials, the risk for clinically significant weight gain was greater with olanzapine than with asenapine, and that risk increased with extended treatment. Changes from baseline in metabolic chemistries, laboratory tests and vital signs were generally small and not clinically relevant, although prolactin levels were slightly greater with olanzapine than with asenapine. Compared with olanzapine, asenapine was less likely to cause dry mouth and weight gain, but more likely to cause dizziness, nausea, akathisia, and oral hypoesthesia.

In conclusion, this review indicates that asenapine is efficacious and not inferior to olanzapine in the treatment of mixed or manic episodes associated with BD-I in the short-term and long-term. It is also well-tolerated, with a low incidence of side effects, the most common of which are somnolence, akathisia, dizziness, nausea, weight gain and oral hypoesthesia due to its sublingual administration. Most adverse events were mild to moderate in severity. Moreover it seems that asenapine's weight gain profile is better than that associated with several other second-generation antipsychotics, including olanzapine. Importantly, it has no appreciable effect on metabolic laboratory parameters.

Asenapine is administered through a sublingual route which could be an advantage in a patient population that refuses to swallow. The disadvantages are twice-daily dosing (because an increase in dosing frequencies seem to have a negative effect on the compliance of patients to the 
treatment), and there is also a need to avoid food and drink for 10 minutes after dosing. Because of the small number of trials to date, the therapeutic impact of asenapine on the treatment of bipolar disorder requires further clinical investigation.

\section{Disclosure}

The authors received no financial support from producers of asenapine, nor are there any commercial interests involved in this report. Dr Pompili has served as a consultant with Schering-Plough Corporation Italy, or has engaged in research collaborations with Eli Lilly and Astra Zeneca and received travel support from Servier and Stroder. Dr Serafini has served as a consultant to, or engaged in research collaborations with Bristol-Myers Squibb, Janssen, Eli Lilly, Glaxo Smith Kline and AstraZenaca. Dr Tatarelli has served as a consultant to, or engaged in research collaborations with Eli Lilly, Janssen, Merck, Bristol-Myers Squibb, and Servier Corporations. Dr Girardi has served as a consultant to, or has engaged in research collaborations with Organon, Eli Lilly, Janssen, Merck, Bristol-Myers Squibb, Pfizer, and AstraZeneca Corporations. Other authors have no relevant disclosures. No author is a member of pharmaceutical speakers' panels, nor do they or any family members hold equity positions in pharmaceutical or biotechnology companies.

\section{References}

1. Pompili M, Rihmer Z, Innamorati M, Lester D, Girardi P, Tatarelli R. Assessment and treatment of suicide risk in bipolar disorders. Expert Rev Neurother. 2009;9(1):109-136.

2. Vieta E, Sanchez-Moreno J. Acute and long-term treatment of mania. Dialogues Clin Neurosci. 2008;10(2):165-179.

3. Moller HJ, Demyttenaere K, Sacchetti E, Rush AJ, Montgomery SA. Improving the chance of recovery from the short- and long-term consequences of depression. Int Clin Psychopharmacol. 2003; 18(4): 219-225.

4. Demyttenaere K, Enzlin P, Dewe W, et al. Compliance with antidepressants in a primary care setting, 2: the influence of gender and type of impairment. J Clin Psychiatry. 2001;62(Suppl 22):34-37.

5. Peveler R, George C, Kinmonth AL, Campbell M, Thompson C. Effect of antidepressant drug counselling and information leaflets on adherence to drug treatment in primary care: randomised controlled trial. BMJ. 1999; 319(7210):612-615.

6. Melfi CA, Chawla AJ, Croghan TW, Hanna MP, Kennedy S, Sredl K. The effects of adherence to antidepressant treatment guidelines on relapse and recurrence of depression. Arch Gen Psychiatry. 1998;55(12): $1128-1132$.
7. Thase ME, Nierenberg AA, B. KM, Panagides J. Efficacy of mirtazapine for prevention of depressive relapse: a placebo controlled double-blind trial of recently remitted high-risk patients. J Clin Psychiatry. 2001; 62(10):782-788.

8. Lingam R, Scott J. Treatment non-adherence in affective disorders. Acta Psychiatr Scand. 2002;105(3):164-172.

9. Muller-Oerlinghausen B, Berghofer A, Ahrens B. The antisuicidal and mortality-reducing effect of lithium prophylaxis: consequences for guidelines in clinical psychiatry. Can J Psychiatry. 2003;48(7): 433-439.

10. Tondo L, Isacsson G, Baldessarini R. Suicidal behaviour in bipolar disorder: risk and prevention. CNS Drugs. 2003;17(7):491-511.

11. Craig TJ, Ye Q, Bromet EJ. Mortality among first-admission patients with psychosis. Compr Psychiatry. 2006;47(4):246-251.

12. Dutta R, Boydell J, Kennedy N, Van Os J, Fearon P, Murray RM. Suicide and other causes of mortality in bipolar disorder: a longitudinal study. Psychol Med. 2007;37(6):839-847.

13. Khalsa HM, Salvatore P, Hennen J, Baethge C, Tohen M, Baldessarini RJ. Suicidal events and accidents in 216 first-episode bipolar I disorder patients: predictive factors. J Affect Disord. 2008;106(1-2):179-184.

14. Meltzer HY, Dritselis A, Yasothan U, Kirkpatrick P. Asenapine. Nat Rev Drug Discov. 2009;8(11):843-844.

15. Hussar DA, Abbas CA. New drugs: asenapine, iloperidone, and bepotastine besilate. J Am Pharm Assoc (2003). 2010;50(1):107-110.

16. Minassian A, Young JW. Evaluation of the clinical efficacy of asenapine in schizophrenia. Expert Opin Pharmacother. 2010;11(12):2107-2115.

17. Citrome L. Asenapine for schizophrenia and bipolar disorder: a review of the efficacy and safety profile for this newly approved sublingually absorbed second-generation antipsychotic. Int J Clin Pract. 2009; 63(12):1762-1784.

18. McIntyre RS, Cohen M, Zhao J, Alphs L, Macek TA, Panagides J. A 3-week, randomized, placebo-controlled trial of asenapine in the treatment of acute mania in bipolar mania and mixed states. Bipolar Disord. 2009;11(7):673-686.

19. McIntyre RS, Cohen M, Zhao J, Alphs L, Macek TA, Panagides J. Asenapine for long-term treatment of bipolar disorder: a double-blind 40-week extension study. J Affect Disord. 2010;126(3):358-365.

20. McIntyre RS, Cohen M, Zhao J, Alphs L, Macek TA, Panagides J. Asenapine in the treatment of acute mania in bipolar I disorder: a randomized, double-blind, placebo-controlled trial. J Affect Disord. 2010;122(1-2):27-38.

21. McIntyre RS, Cohen M, Zhao J, Alphs L, Macek TA, Panagides J. Asenapine versus olanzapine in acute mania: a double-blind extension study. Bipolar Disord. 2009;11(8):815-826.

22. Young RC, Biggs JT, Ziegler VE, Meyer DA. A rating scale for mania: reliability, validity and sensitivity. Br J Psychiatry. 1978;133: 429-435.

23. McIntyre RS. Asenapine: A review of acute and extension phase data in bipolar disorder. CNS Neurosci Ther. 2010 Oct 15. doi: 10.1111/j.1 755-5949.2010.00200.x. [Epub ahead of print].

24. Weber J, McCormack PL. Asenapine. CNS Drugs. 2009;23(9): 781-792.
Neuropsychiatric Disease and Treatment

\section{Publish your work in this journal}

Neuropsychiatric Disease and Treatment is an international, peerreviewed journal of clinical therapeutics and pharmacology focusing on concise rapid reporting of clinical or pre-clinical studies on a range of neuropsychiatric and neurological disorders. This journal is indexed on PubMed Central, the 'PsycINFO' database and CAS, and is the official

\section{Dovepress}

journal of The International Neuropsychiatric Association (INA). The manuscript management system is completely online and includes a very quick and fair peer-review system, which is all easy to use. Visit http://www.dovepress.com/testimonials.php to read real quotes from published authors. 